\title{
The 1956 contribution to economic growth theory by Robert Solow: a major landmark and some of its undiscovered riches
}

\author{
Olivier de La Grandville*
}

\begin{abstract}
The famous '1956' contribution by Robert Solow was always thought to be central to positive, or descriptive, economic growth theory. We show that it is also at the core of optimal growth, because the Fisher equation of competitive equilibrium is nothing short of an Euler equation; it corresponds to the maximization of the sum of discounted consumption flows. From this equation an optimal savings rate results with reasonable, very reachable values. We also show the importance of the elasticity of substitution: there is a threshold value of this parameter leading to a permanent growth rate of income per person that is above the labour-augmenting rate of technical progress, and that rate does depend upon the investment-saving ratio.
\end{abstract}

Key words: economic growth, competitive equilibrium, Euler equation, optimal economic growth, elasticity of substitution

JEL classification: B1, B2, O4

\section{Introduction}

At the very origin of economics, the theory of economic growth has a rich and beautiful history. In Western societies, the earliest contributions to the field date back to the sixteenth and seventeenth centuries only; we owe them to Botero $(1589,1598)$, Serra (1613), Sully (1634), and Child (1668). But it is not until the writings of Turgot (1766) and Smith (1776) that a systematic exploration of the causes of economic growth was made. As often in science, a theory could be developed only on the basis of observations - and the period that followed the Middle Ages, in particular the fourteenth century, was one of the darkest episodes in the history of the Western world, certainly comparable to what was experienced by humanity in the twentieth century. In those times, there was no chance that anyone would even ponder the possibility of development. As the French historian Pierre Gaxotte once wrote: 'The man of the Middle Ages does not know of time and numbers.'

\footnotetext{
*University of Geneva, e-mail: olivier.delagrandville@ecopo.unige.ch doi: $10.1093 /$ icb/grm005

(C) The Author 2007. Published by Oxford University Press.

For permissions please e-mail: journals.permissions@oxfordjournals.org
} 
It is not surprising, therefore, that we owe to Arab civilization the first exploration of the economic growth process. With his Introduction to History (The Muqquaddimah, 1377), Ibn Khaldun has bequeathed us not only some of the foundations of contemporary economic growth theory, but a sweeping vision of the causes of the rise and decline of civilizations. This is a good place to recall what Arnold Toynbee (1935) had to say about Ibn Khaldun's magnum opus: 'Undoubtedly the greatest work of its kind that has ever yet been created by any mind in any time or place.'

The development of the theory was far from linear. For many decades it did not budge. Outstanding contributions were ignored for centuries (that of Ibn Khaldun is an example). Some correct ideas, which would prove essential later in the quantification of the growth process, were not put to work: for instance, Smith's fundamental idea that output could be increased by the very fact that the marginal productivity of labour is an increasing function of capital was never formalized until Wicksell (in 1901) came up with the general power function of capital and labour, in a treatise published initially in Swedish. Three decades passed until Cobb and Douglas independently rediscovered it (1928), and then it waited another 30 years to be put to use. In the meantime, economists embarked upon rigid, unduly restrictive assumptions about the functioning of the economy.

We can safely say that by the eighteenth century the qualitative growth process was well understood. It is only when economists tried to describe the evolution of the economy by building quantitative models that things started to fall apart. For reasons that are difficult to track down, in the first part of the twentieth century a fixed relationship was posited between factor inputs and output. This took the form either of a product proportional to the stock of capital, or the form of a function equal to $\min (K / a, L / b)$ where $a$ and $b$ are constants. In one form or another this led Cassel (1918), Lundberg (1937), Harrod (1948), and Domar (1946) to dire predictions about the future of the economy: it was bound either to a waste of resources or to ever-increasing unemployment, unless the growth rate of labour happened to be exactly equal to the savings rate divided by the fixed capital-output ratio.

This is where Robert Solow's Nobel Prize winning essay (Solow, 1956) enters the picture. The rigidity of the initial model of growth was shown to be the culprit for those dire predictions. But the essay went way beyond that. It answered some fundamental questions about our future, namely: what are sufficient conditions for income per person to increase, even in the absence of technological progress? And if those conditions are met, will income per person tend to a limit, or will it increase forever?

One of the beauties of the essay is that those questions could be answered with one stroke of the pen, just by drawing the phase diagram of the differential equation governing the motion of the economy. If $Y=F(K, L)$ is homogeneous of degree one with $F_{K}>0$ and $F_{L}>0$, then income per person $y$ is just a function of the capital-labour ratio $r ; y=Y / L=F(K / L, 1)=f(r)$, and $f^{\prime}(r)=F_{K}>0$. So all conclusions about the evolution of $y$ can be reached through the analysis of the evolution of $r$. In turn, if investment $\dot{K}$ is a proportion $s$ of $Y$ and if $\dot{L} / L=n$, the equation of motion of $r$ is

$$
\dot{r}=s f(r)-n r .
$$

Hence $r$ is governed by an autonomous differential equation, which can be represented graphically in $(r, \dot{r})$ space. Simply knowing the outlook of $f(r)$ (the vertical section of $F(K, L)$ at $L=1)$ and the parameters $s$ and $n$ enables us immediately to conclude on the evolution of $r$ and $y$. Only qualitative properties of $f(r)$ are needed to infer the existence and 
the properties of equilibrium points. In particular, it could be immediately seen under what circumstances income per person would grow forever.

\section{Uncovering riches}

We believe that there are at least two areas that were opened up in Robert Solow's essay that have not been fully exploited until now. The first is the benefits an economy can derive from an increasing elasticity of substitution. The second one is the as yet undisclosed message contained in the essay about optimal economic growth. In particular, we will show how it is possible to determine the so far elusive, all-important, optimal savings rate of an economy.

\section{The benefits of a high elasticity of substitution}

Robert Solow had given a thorough analysis of three cases, each corresponding to a given production function: the so-called Walras-Leontief production function $Y=\min (K / a, L / b)$; the Cobb-Douglas function $Y=K^{a} L^{1-a}$; and a third function, $Y=\left(a K^{p}+L^{p}\right)^{1 / p}$, to which he attributed no particular name, but which he would introduce 5 years later with fellow authors K. Arrow, H. Chenery, and B. Minhas (Arrow et al., 1961) as the constant elasticity of substitution (CES) production function. In the CES case, the differential equation governing the motion of $r(t)$ has no analytic solution; but the sub-case $p=1 / 2$ chosen by Robert Solow turns out to be relatively simple, in the sense that a solution is available at least in implicit form-although still requiring numerical calculations. Once again, then, the phase diagram would prove of great value, leading to the fundamental result that if the savings (or investment) rate $s$ is sufficiently high (if $s \geq n / a^{2}$ ), the capital-labour ratio increases indefinitely, and so does income per person. If, on the other hand, $s<n / a^{2}$, then $r(t)$ and $y=f[r(t)]$ converge toward finite equilibrium values.

It can be observed that the three cases carry, in succession, increasingly good news: from the disaster entailed by the Walras-Leontief production function, we end up with a possibility of ever-increasing income per person. This prompts us to ask the question: what is the common element in these three cases that is at the source of those additional benefits? The answer is in the hidden parameter: the elasticity of substitution, which increases from 0 to 1 and 2 in each of these cases, respectively. Five years later, Arrow et al. (1961) would observe that the CES function $Y=\gamma\left[\delta K^{p}+(1-\delta) L^{p}\right]^{1 / p}$ is a linear transform of a general mean of $K$ and $L$ of order $p$, with $p=1-1 / \sigma$. They used this fact to deduce at once the particular cases $\gamma \min (K, L)$ for $p=-\infty$ (or $\sigma=0)$, the geometric mean $\gamma K^{\delta} L^{1-\delta}$ for $p=0$ (or $\sigma=1$ ). But, to the best of our knowledge, no other application has been made of this fundamental characteristic of the CES function.

It turns out that a general mean has two important properties. One is well known; to the best of our knowledge, the other one is new; Robert Solow and myself have offered it as a conjecture (La Grandville and Solow, 2006), based upon numerical calculations.

The first property is that the mean is an increasing function of its order. ${ }^{1}$ Consider now the normalized product per head $y=\left[\delta r^{p}+(1-\delta)\right]^{1 / p}$. It is a linear transform of the general

\footnotetext{
${ }^{1}$ On this see Hardy et al. (1952). The fact that the harmonic, the geometric, and the arithmetic means are in increasing order is just a particular illustration of the property (their orders are $-1,0$, and 1 , respectively).
} 
mean of $r$ and 1 . Since $p=1-1 / \sigma$, its order is an increasing function of $\sigma$; thus, for any $r \neq 1$ income per person is an increasing function of $\sigma$. The elasticity of substitution then becomes an efficiency parameter, whose benefits for the economy can be compared to those of a technical progress coefficient. Of course, the first question to be asked is the threshold value of $\sigma$-and conversely, that of $s$, given $\sigma$-leading to permanent growth, for given values of the other parameters of the system. For a function written as $y=\left[\delta r^{p}+(1-\delta)\right]^{1 / p}$, that threshold for $\sigma$ can be determined ${ }^{2}$ as $\hat{\sigma}=1 /[1+(\log \delta) / \log (s / n)]$; it is, reasonably enough, increasing with $n$ and decreasing with $\delta$ and $s$. An extension of this result is available in the central case of labour-augmenting progress at rate $g$. We may ask the question: is there a threshold value of $\sigma$ above which the permanent growth rate of income per person would be guaranteed at a rate above $g$ ? Such a threshold exists: it is given by the former expression of $\hat{\sigma}$ where $n$ is augmented by $g$ (see La Grandville and Solow, 2007); the permanent growth rate is then $s \delta^{\sigma /(\sigma-1)}-n$, which is larger than $g$, and an increasing function of $\sigma$ and $s$.

We now offer the following property: the general mean $\left(\sum_{i=1}^{2} f_{i} x_{i}^{p}\right)^{1 / p}$, where $x_{i}>0$, with $\sum_{i=1}^{2} f_{i}=1$, has one single point of inflexion (see La Grandville and Solow, 2006). This is not yet a theorem, but only a conjecture. The reason is that we have been able to observe this property only numerically. ${ }^{3}$

Why is this property important? Because when the elasticity of substitution is anywhere between 0.8 and 1.2 (its observed range today), income per person turns out precisely to be very close to this point of inflexion. This implies that any change in $\sigma$ has now a maximum impact upon income per person. In turn, it may very well explain partially the miracle growth in South-Asian economies, ${ }^{4}$ as well as the growth in some OECD countries in this last decade, phenomena that may be attributable not necessarily to an increase in technical progress but to an increase in the elasticity of substitution. ${ }^{5}$

\section{A surprise: where Messrs Euler, Fisher, and Solow finally meet}

The 1956 contribution was always considered as the corner-stone of positive, or descriptive, growth theory. We argue here that there is even more to it.

Remember that Robert Solow had described the behaviour of the factor rental prices corresponding to the growth paths implied by his model. In particular, he had shown how the marginal productivity of capital was related to the rate of interest through the Fisher equation.

$$
i(t)=\frac{q(t)}{p(t)}+\frac{\dot{p}(t)}{p(t)}
$$

where $q(t) / p(t)$ is the real rental rate of capital.

Together with the traditional marginal productivity equation, $F_{K}=q(t) / p(t)$, this implied

$$
i(t)=F_{K}\left(K_{t}, L_{t}, t\right)+\dot{p}(t) / p(t)
$$

${ }^{2}$ See La Grandville (1989) and Klump and La Grandville (2000).

${ }^{3}$ The complexity of the second derivative of the general mean does not seem to allow for an analytical proof.

${ }^{4}$ This conjecture was successfully tested by Yuhn (1991).

${ }^{5}$ See La Grandville and Solow (2006). 
where we have indicated explicitly the dependencies of $F_{K}$ upon $K_{t}, L_{t}$, and $t$ in order to allow for technical progress.

At one point, Robert Solow wrote: 'Sometimes it will be convenient to imagine $p$ as constant' (1956, p. 79). Let us now do precisely that, by considering that all our analysis is in real terms. Let us also assume, as Solow did, that depreciation is taken into account and that $Y_{t}=F\left(K_{t}, L_{t}, t\right)$ is net real income. Now the Fisher equation reads simply

$$
i(t)=F_{K_{t}}\left(K_{t}, L_{t}, t\right) .
$$

Innocuous as this familiar equation may seem, it conceals a nice surprise: it is nothing less than an Euler equation. Why should it be, one may ask, since an Euler equation generally is a second-order differential equation, and neither $\dot{K}_{t}$ nor $\ddot{K}_{t}$ appear in (4). But a property of the calculus of variations may now be recalled: if the integrand of the functional to be optimized is an affine transform of the derivative of the extremal, then the Euler equation becomes a simple algebraic equation (see, for instance, Elsgolc, 1962). And this is exactly what happens here. Equation (4) corresponds to the first-order condition of maximizing the integral of discounted consumption flows $\int_{0}^{\infty} C(t) e^{-\int_{0}^{t} i(z) d z} d t$ under the constraint $C_{t}=F\left(K_{t}, L_{t}, t\right)-\dot{K}_{t}$, i.e.

$$
\operatorname{Max}_{K_{t}} V=\int_{0}^{\infty}\left[F\left(K_{t}, L_{t}, t\right)-\dot{K}_{t}\right] e^{-\int_{0}^{t} i(z) d z} d t
$$

Denote the integrand $G\left(K_{t}, \dot{K}_{t}, t\right)$. The Euler equation is

$$
\frac{\partial G}{\partial K_{t}}-\frac{d}{d t} \frac{\partial G}{\partial \dot{K}_{t}}=0
$$

and leads to (4) because $G\left(K_{t}, \dot{K}_{t}, t\right)$ is an affine transform of $\dot{K}_{t}$; indeed, $G$ has the form $G\left(K_{t}, \dot{K}_{t}, t\right)=M\left(K_{t}, t\right) \dot{K}_{t}+N\left(K_{t}, t\right)$ with $M\left(K_{t}, t\right)=-e^{-\int_{0}^{t} i(z) d z}$ and $N\left(K_{t}, t\right)=$ $F\left(K_{t}, L_{t}, t\right) e^{-\int_{0}^{t} i(z) d z}$, both independent of $\dot{K}_{t}{ }^{6}$

The fact that (4) is the Euler equation for the variational problem (5) has important consequences. The first is to bring out the far-reaching, unexpected, role of competitive equilibrium in an uncertain world. Nobody knows the future evolution of the interest rates, or that of any of the parameters in the model. As to the notations $F\left(K_{t}, L_{t}, t\right)$ and $F_{K}^{\prime}\left(K_{t}, L_{t}, t\right)$, innocuous as they may seem, they imply, in fact, that the very structure of the production function may shift through time; for instance, the nature of technological progress may be changing in a way that we can little imagine today. But in the far future people will know of the entire past of those variables and relationships, and they may ask the question: 'Taking into account those trajectories, what should have been the optimal time path of $K_{t}$ such that society had maximized the integral of the discounted consumption flows?' The answer is that the Fisher-Solow equation $i(t)=F_{K}^{\prime}\left(K_{t}, L_{t}, t\right)$ applied at all times, which implies that competitive equilibrium was maintained throughout.

\footnotetext{
${ }^{6}$ This result is not limited to the case of analysis in real terms in a risk-free world, but is perfectly general: if $p(t)$ is the time path of the price level, and if $\rho(z)$ is the economy's risk premium, maximizing the functional $\int_{0}^{\infty} p(t)\left[F\left(K_{t}\right)-\dot{K}_{t}\right] e^{-\int_{0}^{t}[i(z)+\rho(z)] d z} d t$ leads to an integrand $J\left(K_{t}, \dot{K}_{t}, t\right)$ which is also affine in $\dot{K}_{t}$, and thus to an Euler equation which yields, after simplifications, the Fisher-Solow equation $i(t)+\rho(t)=F_{K_{t}}+\frac{\dot{p}(t)}{p(t)}$, where $i(t)$ is augmented by the risk premium $\rho(t)$.
} 
Let us now turn to optimal paths. Equation (4) enables us to determine the optimal time path $K_{t}^{*}$, from which the optimal paths $Y_{t}^{*}=F\left(K_{t}^{*}, L_{t}, t\right), I^{*}=\dot{K}_{t}^{*}$, as well as the (ever elusive) optimal savings rate $s_{t}^{*}=I_{t}^{*} / Y_{t}^{*}$ result. We have shown elsewhere (La Grandville, 2007) that if the economy is driven by a CES production function, with a labour force increasing at a variable rate $n_{t}$, labour-augmenting technical progress at rate $g_{t}$, and constant rate of preference for the present $i$, the optimal savings rate turns out to be

$$
s_{t}^{*}=\left(\frac{\delta}{i}\right)^{\sigma}\left(n_{t}+g_{t}\right) .
$$

Putting numbers in equation (7) leads to very reasonable results. For instance, if at time $t$ we have $\sigma=0.9, \delta=0.3, i=0.05, n_{t}=0.01$, and $g_{t}=0.015$, we get an optimal savings rate $s_{t}^{*}$ equal to 0.125 . This contrasts sharply with the results implied by traditional optimal growth theory which, in the wake of Frank Ramsey's seminal paper (1928), postulates that consumption should be valued through a concave utility function, thus entailing the maximization of $\int_{0}^{\infty} U\left(C_{t}\right) e^{-i t} d t$ under the above constraint.

We feel that for many decades traditional optimal growth theory remained in the realm of theory because each time anybody ventured to put some numbers on the optimal trajectories corresponding to the Euler equation, the strangest of results appeared. To the best of our knowledge, the first numerical solution of the Ramsey problem using Ramsey's utility function was given by Stoléru (1970); he obtained 'optimal' savings rates in the order of 90 per cent. Other authors, dealing with power utility functions, got at some point savings rates exceeding 60 per cent (see Goodwin (1961), for instance).

It seems obvious that a complete, systematic analysis of the consequences entailed by utility functions in optimal growth theory is long overdue. This kind of study would have been very laborious in the $1960 \mathrm{~s}$ - not to mention 1928 - because using utility functions always entails non-linear second-order differential equations which do not have analytical solutions. Today this task is made easier by computer programs designed to solve such problems numerically. We therefore carried out this analysis in La Grandville (2007), mentioned above. We briefly mention the main results.

In the literature on optimal growth theory, two families of utility functions are used, or at least casually declared fit for service. The most frequently referred to is the transformation of the power function $U(C)=\left(C^{\alpha}-1\right) / \alpha(\alpha<1 ; U(C)=\log C$ for $\alpha=0)$; the other one is the negative exponential $U(C)=-\frac{1}{\beta} \exp (-\beta C)(\beta>0)$. We have tested both in the central model of optimal growth theory, maximizing the functional $\int_{0}^{\infty} L_{t} U\left(C_{t} / L_{t}\right) e^{-i t} d t$ and using a CES production function with labour-augmenting technical progress.

The results are compelling. With the power function, the highly unstable equilibrium point can be reached for $\alpha$ values between 0 and 1 only with exceedingly high initial savings rates, often way above 50 per cent. In order to have sensible initial consumption values, one has to resort to choosing negative values for $\alpha$. This in turn has dreadful consequences: first, the utility function is very quickly bounded from above (at $1 / \alpha$ ), society giving practically no value to consumption above a very low level; second, in the vicinity of equilibrium the optimal savings rate is exceedingly low, implying a very weak economy in the long run. None of those hypotheses or outcomes would be acceptable by any society.

The consequences for society are even more disastrous in the case of the negative exponential, because no equilibrium point, however unstable and unreachable with acceptable initial conditions, exists any more! Whatever the initial conditions and the values of $\beta$, the economy is doomed either by the collapse of consumption or by the disappearance of its capital stock. 
We are, therefore, led naturally to maximize directly the sum of discounted consumption flows, which leads in turn to the optimal savings rate $s^{*}$ given by (7). I now owe to Robert Solow the following remark and challenging question: we have implicitly assumed the economy to be at time 0 in a state of competitive equilibrium - and presumably to have been there for some time - because $K_{t}$ is a state variable and cannot jump. Suppose that, after a major catastrophe, such as a war or a natural disaster, we are not initially in such a state of competitive equilibrium. For definitiveness, suppose that initially the marginal productivity of capital is higher than the rate of interest. What then should be the optimal investment policy? Pure variational principles are clearly not applicable, because they would dictate an investment as large as income until equilibrium is restored. We have here a problem to which economic theory or empirics give us few definite answers: the speed of adjustment of economic variables, in case of initial disequilibrium. In this case, however, we may suggest the following solution.

First, observe that competitive equilibrium implies not only optimal economic growth, as we have seen, but also the steady state of the economy. Indeed, for the competitive equilibrium relationship $f^{\prime}(r)=i$ to be maintained, $r$ must be fixed-and therefore it should correspond to the steady state. This can be verified by replacing in (7) the rate of interest $i$ by the marginal productivity of capital $f^{\prime}(r)$ ( $f$ and $r$ are expressed in intensive units), where $f(r)$ corresponds to a CES function with labour-augmenting technical progress. After simplifications, the equality $s f(r)=(n+g) r$, characteristic of the steady state results. Among other consequences, this implies that the optimal savings rate $s^{*}$ can be constructed geometrically as follows (Figure 1). In the phase diagram, first draw the curve $y=f(r)$ and the ray $(n+g) r$. From the curve $y=f(r)$ define the point $r^{*}$ where the slope $f^{\prime}\left(r^{*}\right)$ is equal to $i$. Then $s^{*}$ is just the ratio $(n+g) r^{*} / f\left(r^{*}\right)$, which can be read off the vertical axis

Figure 1: A geometrical construction of the optimal savings rate $s^{*}$ implied by competitive equilibrium

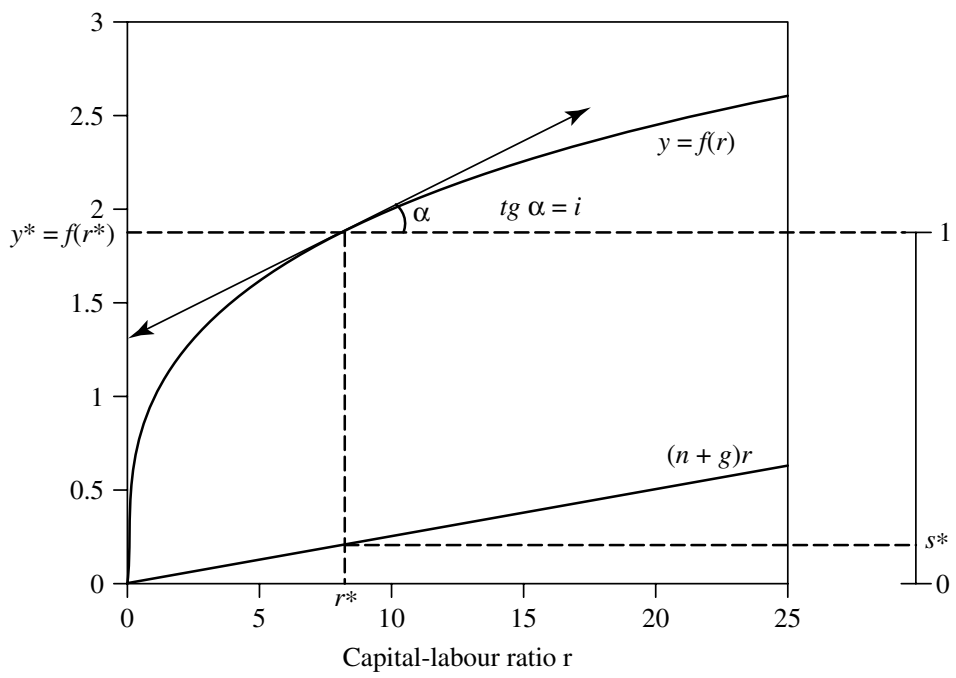

Note: From the curve $y=f(r)$ determine the abscissa $r^{*}$ for which $f^{\prime}\left(r^{*}\right)=i$. Since $r^{*}$ has to be maintained at that level, $s^{*}$ must be such that $s^{*} f\left(r^{*}\right)=(n+g) r^{*}$. So $s^{*}=(n+g) r^{*} / f\left(r^{*}\right)$. If $y=f\left(r^{*}\right)$ is normalized to $1, s^{*}$ is just the height $(n+g) r^{*}$. The existence of competitive equilibrium enforces an equilibrium capital-labour ratio as well as an optimal savings rate. 
(graduated from 0 to 1 ) on the right-hand side of the diagram. In this example, $y=r^{0.3}$; $i=0.075 ; n+g=0.025$; this leads to $r^{*} \approx 7.25$ and $s^{*}=0.1$.

Suppose now that, for whatever reason, the initial capital-labour ratio $r_{0}$ is smaller than $r^{*}$. This implies that $f^{\prime}\left(r_{0}\right)>i$. For equilibrium $r^{*}$ to be reached in finite time, and from that point in time an optimal policy to be followed, it suffices that society adopts a savings rate very slightly above $s^{*}$. Notice the following central property of the optimal savings rate $s^{*}$ : whatever the initial gap between $r^{*}$ and $r_{0}, s^{*}$ is the minimum savings rate necessary for an economy to reach its state of competitive equilibrium $r^{*}$ if initially the capital-labour ratio is below its steady-state value. Symmetrically, it is easy to see that the optimal savings rate $s^{*}$ is the maximum savings rate for the economy to reach its state of competitive equilibrium if initially the capital-labour ratio is above its steady-state value.

\section{Concluding remarks}

Those results should prompt us to redirect optimal growth theory towards the path it would have followed naturally if one had simply asked the question 'What does the Fisher-Solow equation of competitive equilibrium (equation (4) above) imply in terms of savings per unit of income?' The result is not just some odd number: it is an optimal savings rate, since it maximizes the sum of future discounted consumption flows.

In turn this has its rewards. First, and most importantly, contrary to what happens when utility functions are used, optimal time paths for the consumption or the savings rate have now reasonable, very reachable values. Also, optimal time paths as well as society's total discounted consumption flows have now formulas in closed form and lead to analytical comparative dynamics. For instance, the importance of $\sigma$ in the growth process that was surmised in the first part of this paper now finds two theoretical confirmations. First, it can be determined from (7) that, for all commonly observed values of the parameters, the sensitivity of the optimal savings rate $s^{*}$ is higher with respect to a change in $\sigma$ than with respect to any other parameter. Moreover, it can be shown that the maximum value of future consumption flows at society's disposal, $V^{*}=\int_{0}^{\infty} C_{t}^{*} e^{-i t} d t$, is five to six times more sensitive to a change in the elasticity of substitution $\sigma$ than to the same change in the rate of technical progress $g .{ }^{7}$

In the same way as positive growth theory has been impaired by the assumption of rigid relationships between factors and output, it is my view that optimal growth theory has been put on a dead-end road by the introduction of utility functions. And as positive growth theory thrived once it got rid of unrealistic assumptions, I believe that optimal growth theory has

${ }^{7}$ Supposing that $i, n$, and $g$ are constants, it can be shown that $V^{*}=\int_{0}^{\infty} C_{t}^{*} e^{-i t} d t$ is equal to

$$
V^{*}=\frac{1-(\delta / i)^{\sigma}(n+g)}{i-(n+g)}\left\{\delta\left[\frac{1-\delta}{(\delta / i)^{1-\sigma}-\delta}\right]+1-\delta\right\}^{\frac{\sigma}{\sigma-1}}
$$

if $\sigma \neq 1$, and

$$
V^{*}(i, \delta, n, g)=\frac{1-(\delta / i)(n+g)}{i-(n+g)}(\delta / i)^{\frac{\delta}{1-\delta}}
$$

if $\sigma=1$.

The result mentioned in the text is obtained by computing the ratio $\frac{\partial \log V^{*}}{\partial \log \sigma} / \frac{\partial \log V^{*}}{\partial \log g}$ (see La Grandville, 2007). 
a bright future if it does the same and focuses on reasonable hypotheses, entailing policies acceptable to all.

I am sure that all of you are very happy to celebrate this wonderful 50th anniversary. Let me add here a personal note. Like many of you, I have chosen to study economic growth because of the sheer beauty of Robert Solow's essay. But there is something more I would like to share with you. All of us who, year after year, have sent research papers to Bob, either in this area or in another, have received each time extremely insightful comments, as well as deeply thought suggestions. For this rare dedication to our profession, for Bob's kindness and humour, in one word for his humanity, I would like you to join me in an exceedingly heartfelt round of applause.

\section{References}

Arrow, K. J., Chenery, H. B., Minhas, B. S., and Solow, R. M. (1961), 'Capital-Labour Substitution and Economic Efficiency', Review of Economics and Statistics, 43(3), 225-50.

Botero, G. (1589), Della ragione di Stato, Venice; translated and published in English by Routledge \& Kegan Paul, London, 1956.

- (1598), Delle cause della grandezza delle citta, Roma.

Cassel, G. (1918), Theoretische Sozialökonomie, Leipzig, C. F. Winter. English translation, The Theory of Social Economy, London, T. F. Unwin, 1923.

Child, J. (1668), Brief Observations Concerning Interest, Trade and Money, London, E. Calvert.

Cobb, C. W., and Douglas, P. H. (1928), 'A Theory of Production', American Economic Review (Papers and Proceedings), 18(1), 139-65.

Domar, E. (1946), 'Capital Expansion, Rate of Growth and Employment', Econometrica, 14(1), 137-47.

Elsgolc, E. (1962), Calculus of Variations, London, Pergamon Press.

Goodwin, R. M. (1961), 'The Optimal Growth Path for an Underdeveloped Economy', The Economic Journal, 71(284), 756-74.

Hardy, G., Littlewood, J. E., and Polya, G. (1952), Inequalities, 2nd edn, Cambridge, Cambridge University Press; reprinted 1999.

Harrod, R. F. (1948), Toward a Dynamic Economics, London, Macmillan.

Khaldun, I. (1377), The Muqquaddimah-An Introduction to History, translation by F. Rosenthal, London, Routledge \& Kegan Paul, 1958.

Klump, R., and La Grandville, O. de (2000), 'Economic Growth and the Elasticity of Substitution: Two Theorems and Some Suggestions', American Economic Review, 90(1), 282-91.

- Preissler, H. (2000), 'CES Production Functions and Economic Growth', Scandinavian Journal of Economics, 102(1), 41-56.

La Grandville, O. de (1989), 'In Quest of the Slutsky Diamond', American Economic Review, 79(3), 468-81.

- (2007), Economic Growth: A Unified Approach, forthcoming.

- Solow, R. M. (2006), 'A Conjecture on General Means', Journal of Inequalities in Pure and Applied Mathematics, 7(1).

- - (2007), 'Capital-Labour Substitution and Economic Growth', in La Grandville (2007), ch. 4.

Lundberg, E. (1937), Studies in the Theory of Economic Expansion, Westminster, P. S. King \& Son.

Ramsey, F. (1928), 'A Mathematical Theory of Saving', The Economic Journal, 38(152), 543-59.

Serra, A. (1613), Breve trattato delle cause che possono far abbondare li regni d'oso e argento dove non sono miniere, Naples, Lazzaro Scorriggio.

Smith, A. (1776), An Inquiry into the Nature and Causes of the Wealth of Nations, 1977 edn, New York, J. M. Dent.

Solow, R. M. (1956), 'A Contribution to the Theory of Economic Growth', Quarterly Journal of Economics, 70(1), 65-94.

Stoléru, L. (1970), L'équilibre et la croissance économiques — Principes de macroéconomie, Paris, Dunod.

Sully, Maximilien de Béthune, Duc de (1634), Mémoires des sages et royales économies, Paris. 
Toynbee, A. J. (1935), A Study of History, 2nd edn, London.

Turgot de l'Aulne, A. R. (1766), Réflexions sur la formation et la distribution des richesses, Paris.

Wicksell, K. (1901), Föreläsnigar i Nationalekonomi, Häft I, Stockholm/Lund, Fritzes, Berlingska. (Translation of the 3rd Swedish edn (1928) by E. Classen as Lectures on Political Economy, vol. 1: General Theory, London, Routledge \& Kegan Paul, 1934.

Yuhn, K.-H. (1991), 'Economic Growth, Technical Change Biases, and the Elasticity of Substitution: A Test of the de La Grandville Hypothesis', Review of Economics and Statistics, 73(2), 340-6. 